\title{
Numerical Simulation of Barotropic Tides around Taiwan
}

\author{
Chih-Kai Hu${ }^{1,3}$, Chao-Tsung Chiu ${ }^{1,3}$, Shao-Hua Chen ${ }^{1,3}$, \\ Ja-Yu Kuo ${ }^{3}$, Sen Jan ${ }^{1,4, *}$, and Yu-Heng Tseng ${ }^{2}$ \\ ${ }^{1}$ Institute of Hydrological and Oceanic Sciences, National Central University, Jhongli 32001, Taiwan, ROC \\ ${ }^{2}$ Department of Atmospheric Science, National Taiwan University, Taipei 10617, Taiwan, ROC \\ ${ }^{3}$ Taiwan Ocean Research Institute, National Applied Research Laboratories, Taipei 10636, Taiwan, ROC \\ ${ }^{4}$ Institute of Oceanography, National Taiwan University, Taipei 10617, Taiwan, ROC
}

Received 18 November 2008, accepted 25 May 2009

\begin{abstract}
A $1 / 12^{\circ}, 2-\mathrm{D}$ barotropic tide model was used to examine the characteristics of barotropic tides and to improve the accuracy of predicting tidal sea levels and currents in the seas around Taiwan. The form ratio suggests that tides are predominantly semidiurnal in the northern reaches of the Taiwan Strait and mixed of diurnal and semidiurnal elsewhere around Taiwan. When the dominant $\mathbf{M}_{2}$ wave enters the Strait from the north, its amplitude is magnified to $\sim 2 \mathrm{~m}$ in the middle, and then decreases rapidly toward the south end of the Strait. The predominance of diurnal tides along the southwest to the south coast of Taiwan is attributed to the quasi-resonance of diurnal waves in the South China Sea. The tidal range is small and tidal currents are weak off the east coast of Taiwan. Barotropic tidal energy is mostly dissipated on the shallow banks of the southwestern Strait. Results summarized from sensitivity tests on the bottom drag coefficient $\left(C_{D}\right)$ and horizontal eddy viscosity $\left(A_{M}\right)$ indicate that $C_{D}=0.0015-0.00175$ and $A_{M}=150 \mathrm{~m}^{2} \mathrm{~s}^{-1}$ lead to the best model-data fit when compared to the observed tidal sea levels at ten reference tide-gauge stations around Taiwan. The averaged root-mean-squared (RMS) differences of the simulated tidal sea level for the six principal constituents of $\mathrm{O}_{1}, \mathrm{P}_{1}, \mathrm{~K}_{1}, \mathrm{~N}_{2}, \mathrm{M}_{2}$, and $\mathrm{S}_{2}$ are significantly reduced to 1.3, 0.7, 2.0, $1.6,5.1$, and $3.1 \mathrm{~cm}$, respectively, compared to that calculated from a $0.5^{\circ}$ resolution global tide harmonic constant database, NAO.99b (Matsumoto et al. 2000). The averaged RMS differences of barotropic tidal currents $(U, V)$ for $\mathrm{O}_{1}, \mathrm{~K}_{1}, \mathrm{M}_{2}$, and $\mathrm{S}_{2}$ are $(0.92,1.64),(1.17,0.61),(3.88,2.37)$, and $(1.52,1.20) \mathrm{cm} \mathrm{s}^{-1}$. A database of tidal sea levels and current harmonic constants, TWTIDE08, for $\mathrm{Q}_{1}, \mathrm{O}_{1}, \mathrm{P}_{1}, \mathrm{~K}_{1}, \mathrm{~J}_{1}, \mathrm{OO}_{1}, 2 \mathrm{~N}_{2}, \mu_{2}, \mathrm{~N}_{2}, v_{2}, \mathrm{M}_{2}, \mathrm{~L}_{2}, \mathrm{~T}_{2}, \mathrm{~S}_{2}$, and $\mathrm{K}_{2}$ is established with this study.
\end{abstract}

Key words: Numerical model, Barotropic tide, Harmonic constant, Database, Taiwan

Citation: Hu, C. K., C. T. Chiu, S. H. Chen, J. Y. Kuo, S. Jan, and Y. H. Tseng, 2010: Numerical simulation of barotropic tides around Taiwan. Terr. Atmos. Ocean. Sci., 21, 71-84, doi: 10.3319/TAO.2009.05.25.02(IWNOP)

\section{INTRODUCTION}

Barotropic tides in East Asian waters (Fig. 1) have been studied at great length using observed tidal sea levels and currents supplemented with numerical tide models. The purpose of these investigations can be categorized into two groups, an analysis of the dynamics responsible for tidal wave behavior (e.g., Ye and Robinson 1983; Yanagi and Takao 1998; Fang et al. 1999; Jan et al. 2002; Jan et al. 2004a); and improvement in the accuracy of the numerical tide model (e.g., Kang et al. 1998; Lefevre et al. 2000; Matsumoto et al. 2000; Jan et al. 2004b). As summarized from

\footnotetext{
* Corresponding author

E-mail:senjan@ntu.edu.tw
}

these studies, barotropic tidal waves are dominated by semidiurnal constituents in the Northwest Pacific Ocean which propagate essentially westward to the East China Sea (ECS) and to the semi-enclosed South China Sea (SCS). When the tidal waves propagate onto the shallow shelf of the ECS, the dominant waves remain semidiurnal and their amplitude is magnified due to quarter wave resonance. When the tidal waves propagate into the SCS through the Luzon Strait, the dominant waves become diurnal, which is also due to quarter wave resonance for diurnal tides in the SCS. The semidiurnal tidal waves in the ECS split into two directions as they approach the coast around the Chang River ( $a k a$ Changjiang or Yangtze River) mouth, with one propagating northward 


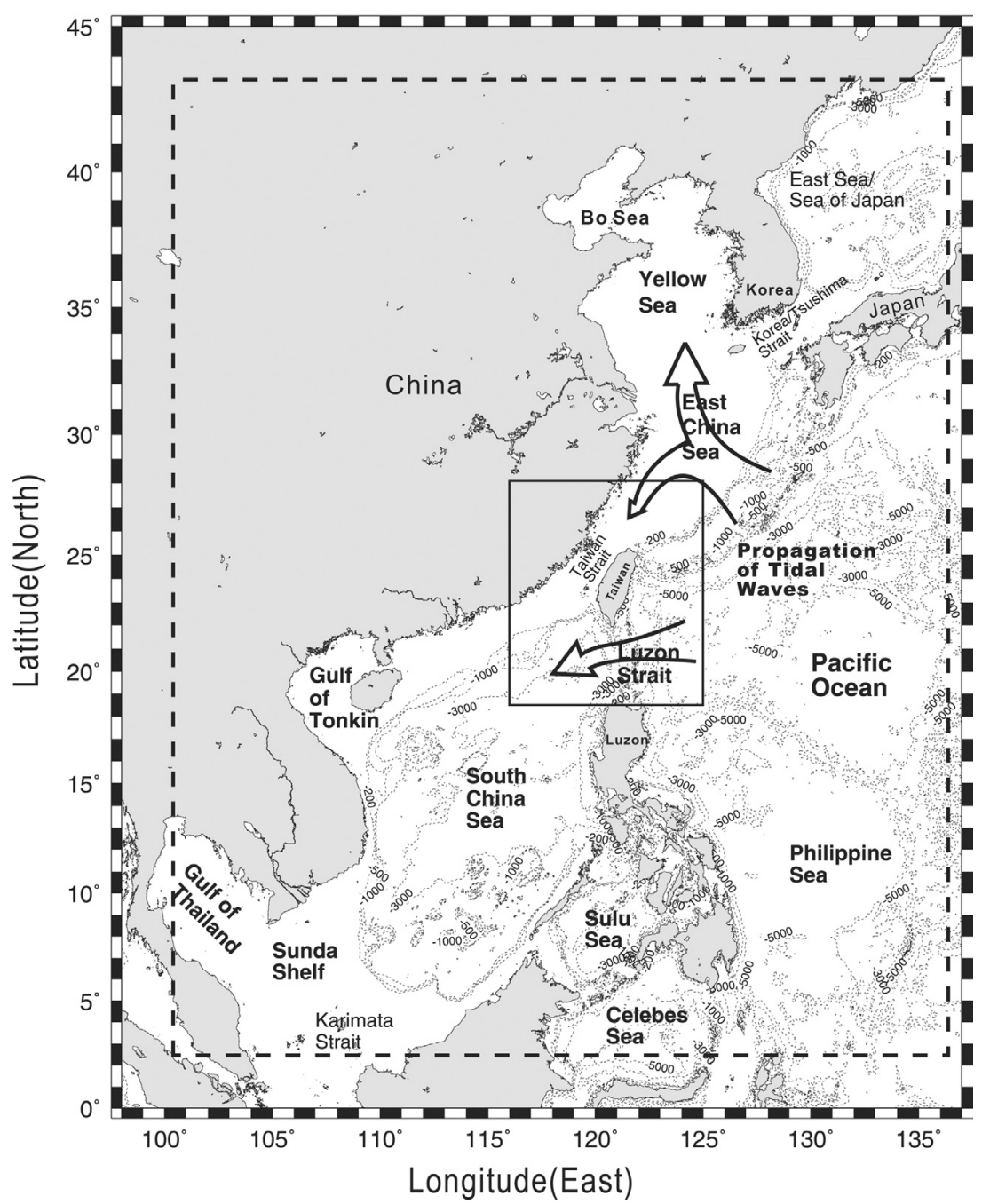

Fig. 1. Bathymetry of the East Asian seas. The dashed rectangle denotes the model domain of this study and the solid rectangle encloses the seas around Taiwan. The propagation of barotropic tidal waves is schematically indicated by arrows.

to the Yellow and Bo Seas and the other going southward to the southern end of the Taiwan Strait. The diurnal tidal waves in the SCS, on the other hand, are significantly amplified after propagating through the Luzon Strait.

According to published co-tidal charts (e.g., Fang et al. 1999; Lefevre et al. 2000), tidal amplitude is relatively large (>2 $\mathrm{m}$ ) along the west coast of Korea and in the Taiwan Strait. The associated barotropic tidal currents are exceptionally strong $\left(>1 \mathrm{~m} \mathrm{~s}^{-1}\right)$ along the west coast of Korea and the northern coast of Taiwan and on the shallow bank in the southwestern Taiwan Strait. Several amphidromic points present in the Yellow Sea and the Gulf of Thailand.

The accuracy of the simulated tidal sea levels is often evaluated by the root-mean-squared difference (hereafter the RMS difference) between the observed and modeled tidal sea levels. This study compared the RMS difference between different tide models for the primary semidiurnal and diurnal constituents, i.e., $\mathrm{M}_{2}$ and $\mathrm{K}_{1}$. Lefevre et al. (2000) conducted a numerical model study using a finite element model (hereafter FES94.1) for tides in the Yellow and East China Seas. The distance between two nodes is approximately $30 \mathrm{~km}$ in the deep ocean and $5 \mathrm{~km}$ along coastlines. The RMS differences of FES94.1 simulated $\mathrm{M}_{2}$ and $\mathrm{K}_{1}$ tides are approximately 15.8 and $5.1 \mathrm{~cm}$, respectively, in the seas around Taiwan. Similar discrepancies for sea levels calculated by the Center for Space Research global model with $0.5^{\circ}$ grid resolution (hereafter CSR 4.0) developed by Eanes and Bettadpur (1996) are $17.7 \mathrm{~cm}\left(\mathrm{M}_{2}\right)$ and $1.9 \mathrm{~cm}\left(\mathrm{~K}_{1}\right)$. The RMS discrepancies of a two-dimensional (2-D), $0.5^{\circ}$ resolution global tide model with the assimilation of TOPEX/ Poseidon altimeter data (hereafter NAO.99b) developed by Matsumoto et al. (2000) are 15.2 and $2.6 \mathrm{~cm}$ respectively for $\mathrm{M}_{2}$ and $\mathrm{K}_{1}$. By comparison, the respective performance of the three models is mixed. The spatial differences of amplitude for $\mathrm{M}_{1}$ and $\mathrm{K}_{1}$ between NAO.99b and CSR4.0 were further compared, as shown in Fig. 2. Distinct discrepancies, 
especially for $\mathrm{M}_{2}$, appear in the coastal region adjacent to the southeast coast of China and in the Taiwan Strait where the difference is as large as $16 \mathrm{~cm}$. Moreover, a generally accepted concept in tidal simulation is that it is difficult to simulate tides accurately in the coastal regions with a globalor basin-scale tide model. A major cause for the model-data mismatch is the truncation error in the model topography due to insufficient horizontal grid resolution. The aforemen-

(a)

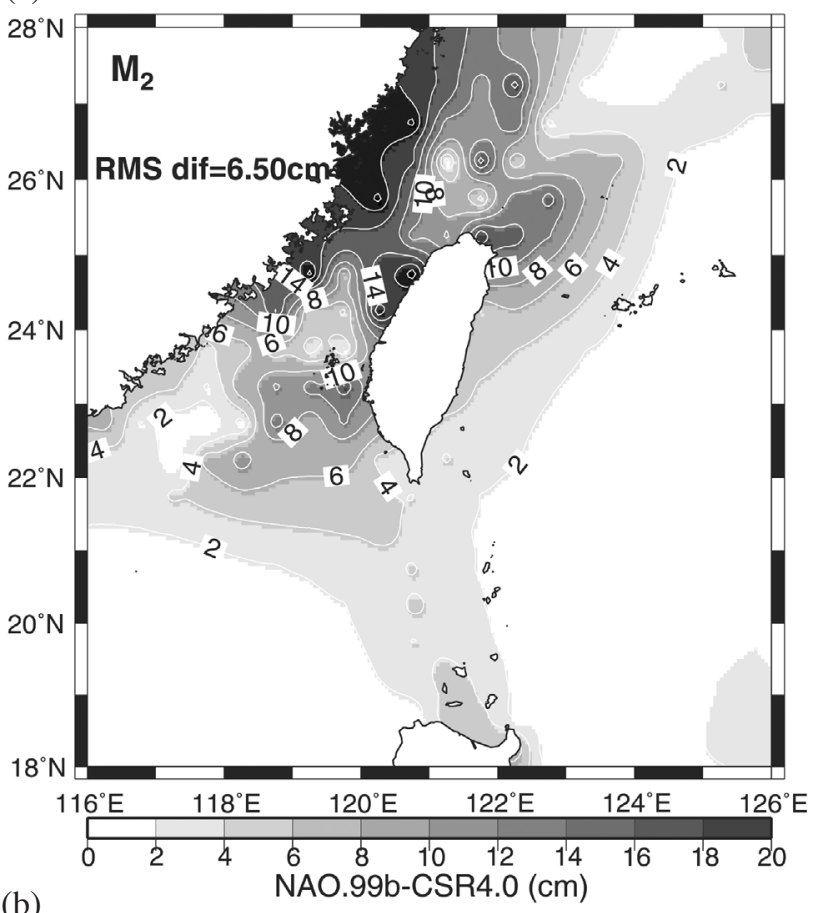

(b)

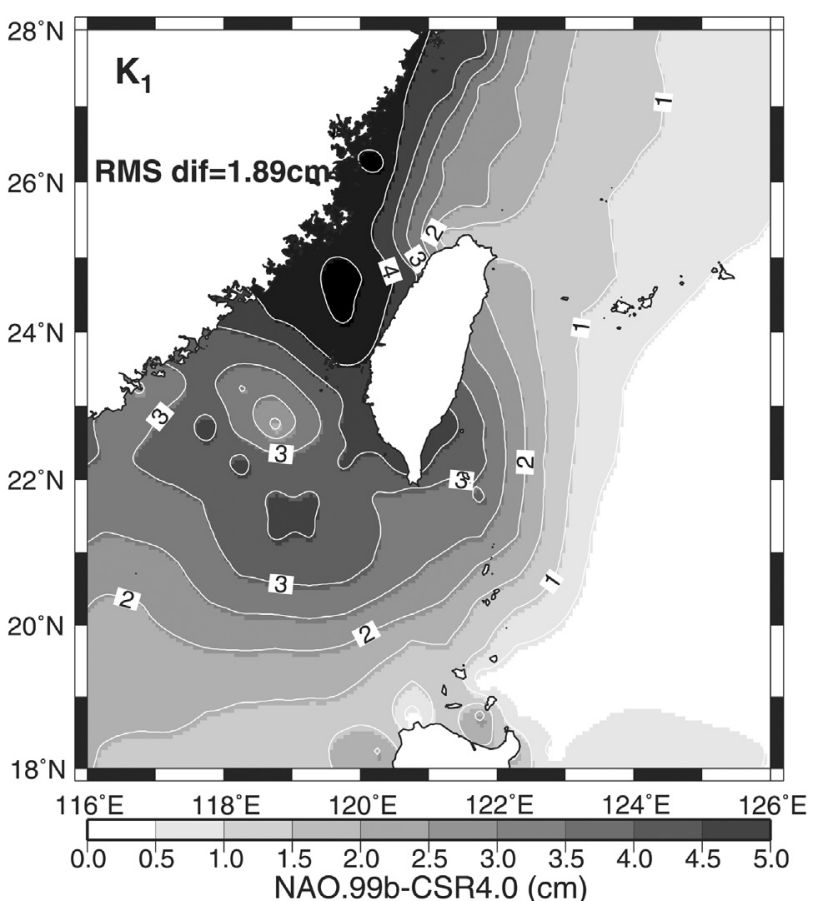

Fig. 2. Spatial variation of the difference in calculated tidal sea levels between NAO.99b and CSR4.0 for (a) $\mathrm{M}_{2}$ and (b) $\mathrm{K}_{1}$. tioned comparisons and concerns justify the need for a more accurate simulation using a higher resolution regional tide model for barotropic tides around Taiwan.

Accurately calculated tides have many applications, including the calculation of ocean tide loading, the removal of barotropic tidal currents from measured ocean current velocities and data correction on a bottom depth measurement. Thus, the objectives of this study are to summarize the characteristics of barotropic tides using observations and model results, and to increase the accuracy of simulated tides as compared to NAO.99b, particularly for the sea around Taiwan. To achieve these objectives, a $1 / 12^{\circ}, 2-\mathrm{D}$ tide model, covering each of the East Asian seas, is developed. A harmonic constant database of barotropic tidal sea levels and currents for fifteen tidal constituents are established along with this study.

\section{DATA AND ANALYSES}

This study concentrates on the simulation of tides in seas around Taiwan between $116-125^{\circ} \mathrm{E}$ and $18.5-28^{\circ} \mathrm{N}$ (the solid rectangle in Fig. 1). Tidal sea levels measured at twenty coastal and island tide-gauge stations around Taiwan (see Fig. 3 for their locations) were collected for this study. Hourly data was used to calculate the harmonic constants using the harmonic analysis method described in Foreman and Henry (1977). The tidal phase in this study refers to Greenwich Mean Time (GMT). Current velocities mea-

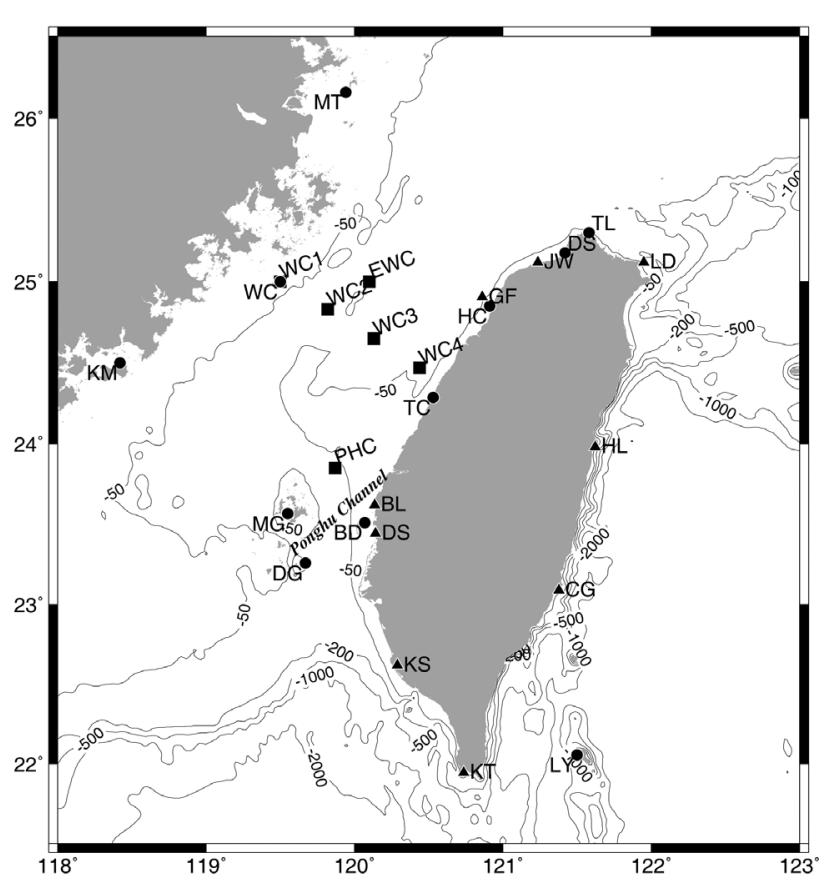

Fig. 3. Locations of tide-gauge stations and bottom-mount ADCP mooring stations. Tidal sea level data collected at stations, as indicated by circles, is used for data assimilation and data collected at stations, as indicated by triangles, is used for evaluation. 
sured at six bottom-mount acoustic Doppler current profiler (ADCP) stations in the Taiwan Strait (Fig. 3) during the project of the Taiwan Strait Nowcast Study (TSNOW) were also utilized to validate the simulated tidal currents.

Results derived from the harmonic analysis suggest that, on average, the fifteen largest dominant tidal constituents are $\mathrm{M}_{2}, \mathrm{~S}_{2}, \mathrm{~K}_{1}, \mathrm{O}_{1}, \mathrm{~N}_{2}, \mathrm{P}_{1}, \mathrm{~K}_{2}, \mathrm{~L}_{2}, v_{2}, \mathrm{Q}_{1}, \mu_{2}, \mathrm{~T}_{2}, 2 \mathrm{~N}_{2}, \mathrm{~J}_{1}$, and $\mathrm{OO}_{1}$. The summation of the first six constituents generally accounted for more than $90 \%$ of the tidal sea level variation. Table 1 lists the harmonic constants for the six principal constituents, $\mathrm{O}_{1}, \mathrm{P}_{1}, \mathrm{~K}_{1}, \mathrm{~N}_{2}, \mathrm{M}_{2}$, and $\mathrm{S}_{2}$, at each tidal station. Along the east coast of China, the tidal amplitude of the dominant $\mathrm{M}_{2}$ reaches a maximum value, $\sim 200 \mathrm{~cm}$, near stations MT and WC. Around the coast of Taiwan, the tidal amplitude peaks near TC, $\sim 200 \mathrm{~cm}$, then decrease towards the northern and the southern tip of Taiwan; the amplitude is small, $\sim 50 \mathrm{~cm}$, along the east coast of Taiwan (LD, HL, CG, and KT).

Table 2 lists the harmonic constants of depth-averaged current velocity components $U$ and $V$ for four primary

Table 1. Tidal sea level harmonic constants for $\mathrm{O}_{1}, \mathrm{P}_{1}, \mathrm{~K}_{1}, \mathrm{~N}_{2}, \mathrm{M}_{2}$, and $\mathrm{S}_{2}$ at twenty tide-gauge stations around Taiwan coast, in which A represents amplitudes in $\mathrm{cm}$ and $\mathrm{G}$ represents phase in degrees. The reference time for phase is GMT (Greenwich Mean Time).

\begin{tabular}{|c|c|c|c|c|c|c|c|c|c|c|c|c|}
\hline \multirow[b]{2}{*}{ St. } & \multicolumn{2}{|c|}{$\mathbf{O}_{1}$} & \multicolumn{2}{|c|}{$\mathbf{P}_{1}$} & \multicolumn{2}{|c|}{$\mathbf{K}_{1}$} & \multicolumn{2}{|c|}{$\mathbf{N}_{2}$} & \multicolumn{2}{|c|}{$\mathbf{M}_{2}$} & \multicolumn{2}{|c|}{$\mathbf{S}_{2}$} \\
\hline & A & G & A & G & A & G & A & G & A & G & A & G \\
\hline MT & 24.15 & 80.7 & 9.71 & 112.8 & 31.99 & 115.0 & 35.25 & 141.1 & 203.78 & 61.1 & 64.94 & 84.6 \\
\hline WC & 25.59 & 97.9 & 11.01 & 134.4 & 34.10 & 144.3 & 35.30 & 164.2 & 209.24 & 87.5 & 62.52 & 119.0 \\
\hline $\mathrm{KM}$ & 25.57 & 105.8 & 11.22 & 143.8 & 34.16 & 152.0 & 31.63 & 185.2 & 179.08 & 106.1 & 54.05 & 144.4 \\
\hline TS & 15.73 & 89.6 & 6.33 & 118.3 & 18.83 & 126.2 & 14.27 & 162.4 & 84.66 & 80.0 & 25.75 & 103.3 \\
\hline $\mathrm{HC}$ & 19.09 & 91.7 & 7.78 & 131.8 & 24.53 & 131.5 & 28.49 & 162.2 & 162.67 & 80.1 & 48.70 & 113.3 \\
\hline $\mathrm{TC}$ & 20.94 & 97.0 & 8.31 & 137.3 & 26.92 & 140.9 & 33.96 & 163.6 & 184.67 & 83.6 & 52.76 & 115.0 \\
\hline BD & 21.62 & 111.1 & 6.81 & 143.7 & 28.15 & 144.6 & 13.48 & 154.1 & 71.52 & 67.2 & 16.59 & 107.9 \\
\hline KS & 19.23 & 119.1 & 6.04 & 136.9 & 21.53 & 154.1 & 3.07 & 96.5 & 22.87 & 353.2 & 13.54 & 335.7 \\
\hline $\mathrm{PH}$ & 20.92 & 110.9 & 7.01 & 146.7 & 25.91 & 152.7 & 15.61 & 164.9 & 84.86 & 81.0 & 21.70 & 123.5 \\
\hline LY & 15.71 & 81.3 & 5.47 & 106.5 & 24.24 & 159.9 & 8.21 & 28.8 & 41.88 & 294.9 & 17.65 & 315.7 \\
\hline KS & 15.91 & 130.0 & 5.78 & 158.2 & 17.19 & 167.0 & 4.02 & 342.3 & 6.73 & 353.1 & 3.37 & 105.7 \\
\hline KT & 20.99 & 113.0 & 7.61 & 144.7 & 23.00 & 137.6 & 5.36 & 317.7 & 27.15 & 318.6 & 13.06 & 343.0 \\
\hline PH & 21.03 & 127.3 & 7.69 & 156.9 & 24.19 & 160.1 & 16.18 & 74.9 & 90.09 & 95.41 & 23.29 & 137.4 \\
\hline CG & 14.75 & 79.2 & 5.85 & 96.9 & 17.54 & 101.5 & 9.65 & 290.3 & 20.6 & 324.8 & 3.02 & 67.7 \\
\hline JW & 18.68 & 99.0 & 7.16 & 122.2 & 22.05 & 126.0 & 23.09 & 61.23 & 121.43 & 82.7 & 34.89 & 115.0 \\
\hline DS & 18.58 & 127.5 & 6.35 & 157.9 & 20.88 & 161.3 & 13.42 & 56.5 & 68.78 & 78.6 & 16.65 & 116.9 \\
\hline $\mathrm{HL}$ & 14.07 & 81.6 & 5.30 & 100.6 & 15.69 & 98.8 & 8.57 & 295.7 & 44.20 & 302.6 & 19.82 & 325.1 \\
\hline GF & 12.06 & 74.0 & 4.85 & 94.5 & 14.40 & 100.4 & 5.40 & 306.6 & 27.73 & 315.1 & 12.00 & 337.6 \\
\hline BL & 19.70 & 124.5 & 7.22 & 155.9 & 22.69 & 157.8 & 20.37 & 64.4 & 104.91 & 86.7 & 27.91 & 125.8 \\
\hline LD & 16.47 & 76.5 & 6.49 & 96.43 & 19.94 & 100.7 & 5.26 & 334.9 & 21.74 & 339.8 & 10.42 & 344.6 \\
\hline
\end{tabular}


constituents, $\mathrm{O}_{1}, \mathrm{~K}_{1}, \mathrm{M}_{2}$, and $\mathrm{S}_{2}$. Tidal currents at the six mooring sites are dominated by the $\mathrm{M}_{2}$ tide, and are nearly aligned along the longitudinal axis of the strait. Barotropic tidal currents are very strong $\left(\sim 0.7 \mathrm{~m} \mathrm{~s}^{-1}\right)$ at the north end of the Penghu Channel (PHC) but relatively weak $\left(<0.06 \mathrm{~m} \mathrm{~s}^{-1}\right)$ off the middle-west coast of Taiwan (WC4). The $\mathrm{K}_{1}$ tidal currents are relatively small $\left(<0.1 \mathrm{~m} \mathrm{~s}^{-1}\right)$ and mostly align along the axis of the strait.

\section{MODEL DESCRIPTION}

The tide model developed in this study was modified from the Princeton Ocean Model which was originally described in Blumberg and Mellor (1987). The model is a depth-integrated, nonlinear, two-dimensional model with the addition of tidal forcing. After taking the vertical integration, the governing equations are as follows.

$$
\begin{aligned}
\frac{\partial U D}{\partial t} & +\frac{\partial U^{2} D}{\partial x}+\frac{\partial U V D}{\partial y}-f \bar{V} D=A_{M} H\left[2 \frac{\partial^{2} U}{\partial x^{2}}\right. \\
& \left.+\frac{\partial}{\partial y}\left(\frac{\partial U}{\partial y}+\frac{\partial V}{\partial x}\right)\right]+F_{x}^{b}+g D \frac{\partial(\zeta-\beta \eta)}{\partial x}
\end{aligned}
$$

$$
\begin{aligned}
\frac{\partial V D}{\partial t} & +\frac{\partial U V D}{\partial x}+\frac{\partial V^{2} D}{\partial y}+f \bar{U} D=A_{M} H\left[2 \frac{\partial^{2} V}{\partial y^{2}}\right. \\
& \left.+\frac{\partial}{\partial x}\left(\frac{\partial U}{\partial y}+\frac{\partial V}{\partial x}\right)\right]+F_{y}^{b}+g D \frac{\partial(\zeta-\beta \eta)}{\partial y}
\end{aligned}
$$

$\frac{\partial \eta}{\partial t}+\frac{\partial U D}{\partial x}+\frac{\partial V D}{\partial y}=0$

where $D(=H+\eta)$ is total ocean depth, $t$ is time, $H$ is mean ocean depth, $\eta$ is sea level variation, $(U, V)$ represent the depth-averaged horizontal velocities in the $x$ and $y$ directions, $f$ is the Coriolis parameter, $A_{M}$ is horizontal viscosity, $\left(F_{x}^{b}, F_{y}^{b}\right)$ are bottom stress components in the $x$ and $y$ directions, $\beta$ ( $=0.940$ for diurnal tides and 0.953 for semidiurnal tides) represents the ocean tide loading which is caused by the deformation of the Earth due to the weight of the ocean tides (Foreman et al. 1993), $\zeta$ is adjusted height of equilibrium tides, and $g$ is the gravitational acceleration. Note that different tidal models may adopt different $\beta$. For example, in the model provided by Niwa and Hibiya (2004), $\beta$ is as-

\begin{tabular}{|c|c|c|c|c|c|c|c|c|c|c|c|c|}
\hline \multirow[b]{2}{*}{ St. } & \multicolumn{2}{|c|}{$\mathbf{O}_{1}$} & \multicolumn{2}{|c|}{$\mathbf{P}_{1}$} & \multicolumn{2}{|c|}{$\mathbf{K}_{1}$} & \multicolumn{2}{|c|}{$\mathbf{N}_{2}$} & \multicolumn{2}{|c|}{$\mathbf{M}_{2}$} & \multicolumn{2}{|c|}{$\mathbf{S}_{2}$} \\
\hline & $\mathbf{A}_{U}$ & $\mathbf{G}_{\mathrm{U}}$ & $\mathbf{A}_{U}$ & $\mathbf{G}_{\mathrm{U}}$ & $\mathbf{A}_{U}$ & $\mathbf{G}_{\mathrm{U}}$ & $\mathbf{A}_{U}$ & $\mathbf{G}_{\mathrm{U}}$ & $\mathbf{A}_{U}$ & $\mathbf{G}_{U}$ & $\mathbf{A}_{U}$ & $\mathbf{G}_{\mathrm{U}}$ \\
\hline WC1 & 5.42 & 260.9 & 2.61 & 314.2 & 7.89 & 307.2 & 5.69 & 243.7 & 25.65 & 257.0 & 7.79 & 285.5 \\
\hline WC2 & 5.37 & 261.8 & 2.46 & 300.8 & 7.42 & 293.8 & 3.85 & 221.5 & 18.69 & 232.2 & 6.69 & 276.0 \\
\hline WC3 & 4.11 & 254.1 & 1.76 & 300.5 & 5.33 & 293.5 & 2.77 & 208.2 & 11.35 & 214.4 & 3.96 & 255.2 \\
\hline WC4 & 2.99 & 264.5 & 1.27 & 297.9 & 3.82 & 290.9 & 1.00 & 211.8 & 3.57 & 223.0 & 1.77 & 269.5 \\
\hline EWC & 6.13 & 237.8 & 3.09 & 288.5 & 9.33 & 281.4 & 4.91 & 183.0 & 28.47 & 204.6 & 9.34 & 248.6 \\
\hline \multirow[t]{2}{*}{ PHC } & 3.10 & 269.8 & 1.43 & 295.1 & 4.32 & 288.1 & 4.96 & 295.6 & 27.70 & 336.2 & 8.71 & 3.51 \\
\hline & $\mathbf{A}_{\mathbf{V}}$ & $\mathbf{G}_{\mathbf{V}}$ & $\mathbf{A}_{\mathbf{v}}$ & $\mathbf{G}_{\mathrm{V}}$ & $\mathbf{A}_{\mathrm{V}}$ & $\mathbf{G}_{\mathbf{V}}$ & $\mathbf{A}_{\mathrm{v}}$ & $\mathbf{G}_{\mathrm{V}}$ & $\mathbf{A}_{\mathbf{V}}$ & $\mathbf{G}_{\mathrm{V}}$ & $\mathbf{A}_{\mathrm{V}}$ & $\mathbf{G}_{\mathbf{V}}$ \\
\hline WC1 & 2.96 & 245.6 & 1.57 & 314.7 & 4.73 & 307.6 & 3.07 & 263.7 & 16.02 & 284.8 & 4.80 & 302.5 \\
\hline WC2 & 3.88 & 272.9 & 1.75 & 308.5 & 5.28 & 301.5 & 3.20 & 262.3 & 15.82 & 284.0 & 5.71 & 313.4 \\
\hline WC3 & 3.61 & 256.1 & 1.66 & 309.3 & 5.03 & 302.3 & 1.98 & 257.6 & 8.88 & 273.7 & 3.38 & 309.4 \\
\hline WC4 & 3.71 & 251.5 & 1.79 & 314.1 & 5.40 & 307.1 & 1.15 & 213.7 & 3.90 & 224.9 & 2.10 & 271.4 \\
\hline EWC & 3.82 & 256.6 & 2.39 & 296.8 & 7.24 & 289.8 & 2.66 & 225.6 & 16.47 & 251.0 & 6.57 & 288.3 \\
\hline PHC & 5.08 & 310.4 & 2.32 & 351.7 & 7.02 & 344.7 & 9.52 & 317.3 & 63.76 & 349.8 & 17.7 & 22.0 \\
\hline
\end{tabular}
sumed to be 0.9 according to Ray (2001). Indeed, $\beta$ is in

Table 2. Tidal current harmonic constants for $U$ and $V$ derived from the model results at the six ADCP stations of $\mathrm{O}_{1}, \mathrm{P}_{1}, \mathrm{~K}_{1}, \mathrm{~N}_{2}, \mathrm{M}_{2}$, and $\mathrm{S}_{2}\left(\mathrm{~A}_{\mathrm{U}}\right.$ and $A_{V}$ : amplitudes in $\mathrm{cm} \mathrm{s}^{-1}, \mathrm{GU}$ and GV: phase in degree; reference time for phase: GMT). 
general not a constant and Ray and Cartwright (1998) suggest that serious errors are sustained by assuming that it is, particularly for tidal models which do not use data assimilation. Nonetheless, the choice of a constant $\beta$ simplifies tidal modeling, and the errors introduced by this approximation are not overly large for most applications (Kantha and Clayson 2000).

The staggered Arakawa $C$ grid was used for the variable arrangement. The bottom stress components are calculated as

$\left(F_{x}^{b}, F_{y}^{b}\right)=C_{D}\left[U^{2}+V^{2}\right]^{0.5}(U, V)$

where $C_{D}$ is a non-dimensional drag coefficient. According to the formulation described in Pugh (1987), the adjusted height of the equilibrium tide is defined as

$\zeta=f_{c} H_{c} \cos \left[\omega_{c} t+\left(V_{0}+\mu\right)+m \lambda\right]$

where $f_{c}$ is the nodal factor; $\omega_{c}$ is the frequency of the corre- sponding tidal constituent; $V_{0}$ is the initial phase angle of the equilibrium tides; $\mu$ is the nodal angle; $m=1$ or 2 accounts for the diurnal or semidiurnal constituents, respectively; $\lambda$ is longitude; subscript $c$ represents the tidal constituent; and $H_{c}\left(=A_{e q} \sin 2 \phi\right.$ or $A_{e q} \cos ^{2} \phi$ for diurnal or semidiurnal tides, $\phi$ : latitude) is the amplitude of the equilibrium tides multiplied by the factor $1+k-h$ ( $k$ and $h$ are Love numbers which are the elastic response and the redistribution of the mass of earth). Table 3 lists $A_{e q}$ for diurnal and semidiurnal constituents, respectively.

The model was bounded from 99.25 to $135.25^{\circ} \mathrm{E}$ and from 2.25 to $43.25^{\circ} \mathrm{N}$ with $1 / 12^{\circ}$ horizontal resolution (Fig. 1). The accuracy of the simulated barotropic tides depended not only on the model itself and the grid resolution but also on the accuracy of the model topography. The bottom topography was established using the revised ETOPO2 (which can be downloaded at http://www.ngdc.noaa.gov/ mgg/global/relief/ETOPO2/ETOPO2v2-2006/ETOPO2v2c/) supplemented with a 1-min depth archive in the region of $105-135^{\circ} \mathrm{E}$ and $2.25-35^{\circ} \mathrm{N}$ provided by the $\mathrm{Na}-$ tional Center for Ocean Research (NCOR) of Taiwan. The

Table 3. Parameters for calculating the adjusted height of equilibrium tides.

\begin{tabular}{cccc}
\hline Constituent & $\begin{array}{c}\text { Amplitude }(\mathbf{c m}) \text { of } \\
\text { equilibrium tide }(\boldsymbol{\xi})\end{array}$ & $\begin{array}{c}\text { Elasticity factor } \\
(\boldsymbol{\alpha}=\mathbf{1}+\boldsymbol{k}-\boldsymbol{h})\end{array}$ & $\begin{array}{c}\boldsymbol{A}_{\boldsymbol{e q}}(=\boldsymbol{\alpha} \xi) \text { for } \\
\text { calculating } \boldsymbol{H}_{\boldsymbol{c}} \text { in Eq. (5) }\end{array}$ \\
\hline $\mathrm{O}_{1}$ & 10.1 & 0.695 & 7.0 \\
$\mathrm{P}_{1}$ & 4.7 & 0.706 & 3.3 \\
$\mathrm{~K}_{1}$ & 14.2 & 0.736 & 10.5 \\
$\mathrm{~N}_{2}$ & 4.7 & 0.693 & 3.3 \\
$\mathrm{M}_{2}$ & 24.4 & 0.693 & 16.9 \\
$\mathrm{~S}_{2}$ & 11.4 & 0.693 & 7.9 \\
$\mathrm{Q}_{1}$ & 1.9 & 0.695 & 1.3 \\
$\mathrm{~J}_{1}$ & 0.8 & 0.691 & 0.6 \\
$\mathrm{OO}_{1}$ & 0.4 & 0.693 & 0.4 \\
$2 \mathrm{~N}_{2}$ & 0.6 & 0.693 & 0.4 \\
$\mu_{2}$ & 0.7 & 0.693 & 0.5 \\
$v_{2}$ & 0.9 & 0.693 & 0.6 \\
$\mathrm{~L}_{2}$ & 0.7 & 0.693 & 0.5 \\
$\mathrm{~T}_{2}$ & 0.7 & 0.693 & 0.5 \\
$\mathrm{~K}_{2}$ & & 0.693 & \\
\hline
\end{tabular}


homogeneous ocean was initially motionless. Subsequently, the model was driven by tidal forcing and prescribed tidal sea levels on all open-ocean boundaries through a forced radiation condition similar to that adopted by Blumberg and Kantha (1985) as

$$
\frac{\partial \eta}{\partial t}+C \frac{\partial \eta}{\partial n}=-\frac{\left(\eta-\eta_{p r e}\right)}{T_{f}}
$$

where $n$ is the normal direction, $C(=\sqrt{g D})$ is the phase speed of a shallow water gravity wave, $\eta_{\text {pre }}$ is the prescribed tidal sea level on open boundaries, and $T_{f}$ is a damping time scale. The term on the right of Eq. (6) indicates damping which tends to force $\eta$ to $\eta_{\text {pre }}$ on open boundaries with a damping time scale of $T_{f}$. According to the explanation in Blumberg and Kantha (1985), $T_{f}=0$ corresponds to a clamped boundary condition for $\eta$ in which no disturbances are allowed to pass through the boundary. When $T_{f}$ tends to be infinity, it represents a pure radiation condition which renders an open boundary transparent to waves propagating in the positive $n$ direction with phase speed $C$. In this study, we adopted $T_{f}=120 \mathrm{~s}$. A zero normal gradient condition, $\partial(U, V) / \partial n=0$, was applied to the depth-averaged tidal current velocity on the open boundaries. The tidal sea levels on open boundaries were composed using the harmonic constants of NAO.99b at every $0.5^{\circ}$ grid. Tidal sea levels at grids between two successive $0.5^{\circ}$ grids were linearly interpolated. Fifteen tidal constituents were simulated and analyzed individually using the model. The mass conservation is typically not a concern in tidal models, especially the volume in a regional tidal model with open boundaries is not necessary to be conserved at each time step. However, the mean sea level which is zero initially in a regional tidal model may drift to a non-zero state after a long time (> 28 days) integration due to round-off and truncation errors. Thus our tidal model computed the mean sea level anomaly and compensated this value to the sea level at each sea grid every 15 days.

\section{RESULTS AND DISCUSSION}

This section presents and discusses the results of the preliminary model runs with $A_{M}=200 \mathrm{~m}^{2} \mathrm{~s}^{-1}$ and $C_{D}=0.0025$. These model runs neither fine tuned nor assimilated tidal sea levels into the model. The co-tidal charts of the principal semidiurnal $\mathrm{M}_{2}$ and diurnal $\mathrm{K}_{1}$ constituents are compared with those from NAO.99b. Figure 4 shows the spatial distribution of tidal amplitude and phase of this study and of NAO.99b for $\mathrm{M}_{2}$ and $\mathrm{K}_{1}$ in our simulation domain. For $\mathrm{M}_{2}$, the co-tidal chart derived from the model run agrees relatively well with that of NAO.99b (Fig. 4a). Two amphidromic points present in the Yellow and Bo Seas and one in the Gulf of Thailand. The spatial variation of the co-phase line indicates that the tidal wave propagated westward from the Pacific Ocean into the East China and Yellow Seas and into the South China Sea through the Luzon Strait. The tidal amplitude is magnified on the shallow East China Sea and decreases as the wave propagated towards the southern SCS.

However, the results of the comparison on $\mathrm{K}_{1}$ are mixed, i.e., fairly well in the Pacific Ocean and the ECS, but rather unsatisfactorily in the SCS. Compared with NAO.99b, tidal amplitude in the SCS is overestimated by $\sim 100 \%$. This is a considerable discrepancy although the absolute difference in amplitude is merely $\sim 20 \mathrm{~cm}$. The lack of energy conversion from the barotropic tides to the generation of the baroclinic tides in the Luzon Strait possibly leads to the overestimation (Jan et al. 2007). Regardless of the discrepancy in the SCS, the fast changing and slow varying of the phases, respectively, in the Luzon Strait and SCS and the increase of amplitude in the SCS suggest that the $\mathrm{K}_{1}$ tide is a quasi-resonant wave. The comparison between ours and the co-tidal charts of NAO.99b suggests the need for fine tuning and data assimilation for better simulation of the diurnal tides in the SCS using a 2-D model. Indeed, in the conclusion of Jan et al. (2007), it was emphasized that a 2-D model could not simulate tidal sea levels satisfactorily without data assimilation in a region of vigorous baroclinic tide generation.

Since one of the objectives of this study is to improve the accuracy of the model results around Taiwan, we assimilate tidal sea levels composed from harmonic constants of NAO.99b at deep water (depth $>200 \mathrm{~m}$ ) and from those at ten of the twenty tide-gauge stations (circles in Fig. 3) to the model. The RMS discrepancies of modeled and NAO.99bcomposed tidal sea levels at the other ten of the twenty coastal tide-gauge stations (triangles in Fig. 3) are evaluated with the observations as below.

\subsection{Sensitivity Runs for $A_{M}$ and $C_{D}$}

Doubtlessly, the model results are affected by lateral friction and bottom drag which are controlled by horizontal eddy viscosity, $A_{M}$, and bottom drag coefficient, $C_{D}$, respectively. To examine how sensitive the modeled tidal sea levels and currents are to the variation of the two parameters, model runs with various $A_{M}$ (from 50 to $300 \mathrm{~m}^{2} \mathrm{~s}^{-1}$ with increment $\left.50 \mathrm{~m}^{2} \mathrm{~s}^{-1}\right)$ but fixed $C_{D}(=0.002)$, and various $C_{D}$ (from 0.001 to 0.003 with increment 0.0005 ) but fixed $A_{M}\left(=200 \mathrm{~m}^{2} \mathrm{~s}^{-1}\right)$ were performed. The accuracy of the simulated tidal sea levels and currents was evaluated with a commonly used parameter, the RMS difference, which considers both amplitude and phase differences between observations and model results, and is defined as

$\mathrm{RMS}=\left[\frac{1}{N-1} \sum_{i=1}^{N}\left(\eta_{i}^{M}-\eta_{i}^{o}\right)^{2}\right]^{1 / 2}$ 
(a)

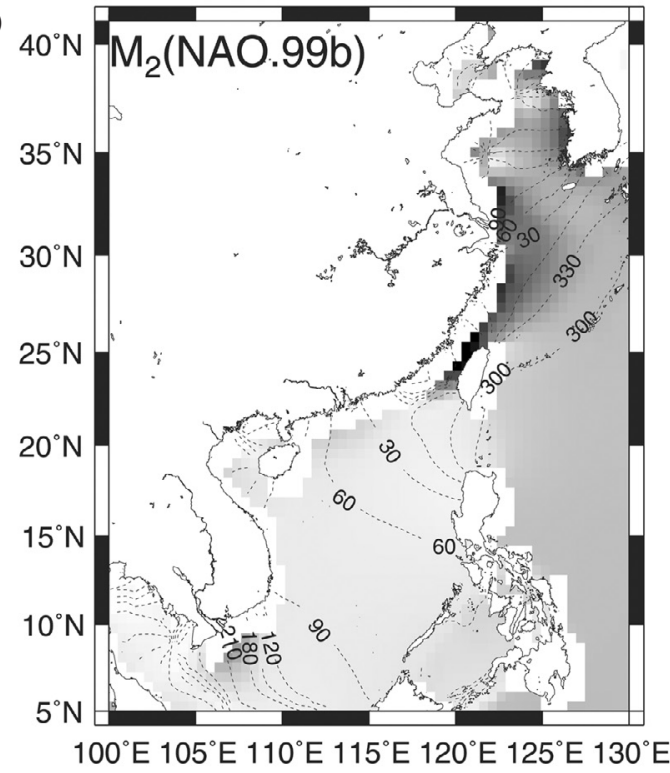

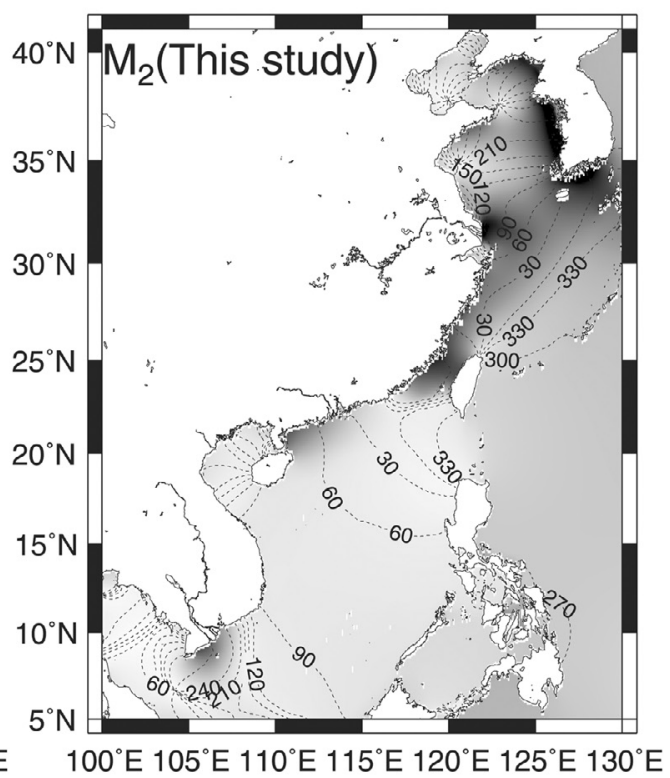

(b)
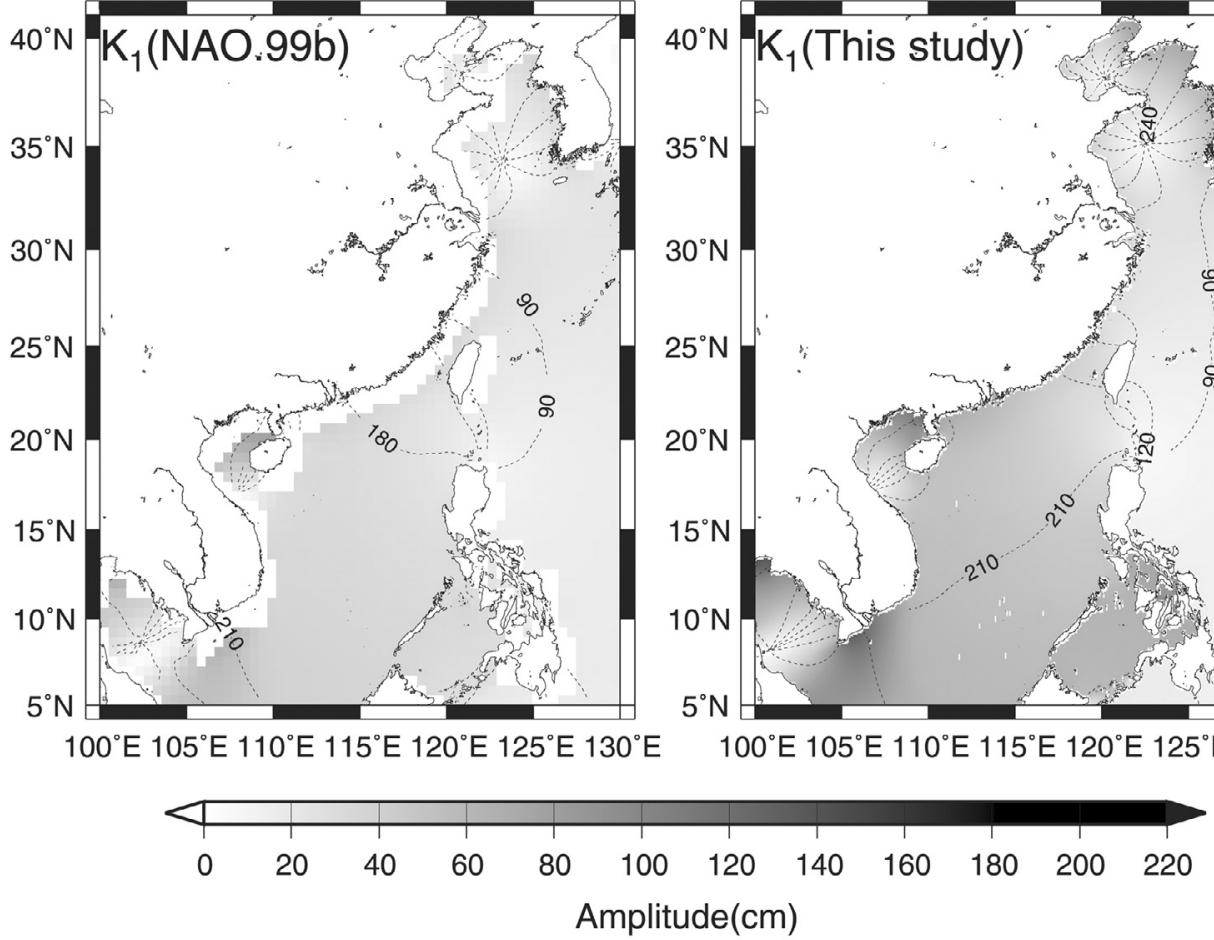

Fig. 4. Co-tidal charts of (a) $\mathrm{M}_{2}$ and (b) $\mathrm{K}_{1}$ derived from basic model runs with $A_{M}=200 \mathrm{~m}^{2} \mathrm{~s}^{-1}$ and $C_{D}=0.0025$. Amplitudes (cm) are indicated by a grey scale. Contours are co-phase lines in degrees.

where $\eta_{i}^{M}=a_{M} \cos (\omega t-\phi)$ is modeled tidal sea level, $\eta_{i}^{o}=$ $a_{o} \cos (\omega t-\varphi)$ is tidal sea level composed by observed harmonic constant $\left(a_{M}\right.$ and $a_{O}$ are modeled and observed amplitudes, $\phi$ and $\varphi$ are modeled and observed phases, and $\omega$ is tidal period in rad), $N=$ integer $[T$ (tidal period in minute) $/ \Delta t]$ is data number in a tidal period with time interval $\Delta t$ (= 10 minute). Tidal sea levels obtained at the other ten of the twenty tide-gauge stations (triangles in Fig. 3), which are not assimilated into the model, and the depth-averaged tidal currents at the six bottom-mount ADCP stations are used as references for the evaluation.

The RMS difference of the tidal sea levels, averaged over the ten tide-gauge stations, and of tidal current speed and direction, averaged over the six ADCP stations, was normalized by the minimum value for each constituent. The normalized RMS difference for the three variables for the six constituents $\left(\mathrm{O}_{1}, \mathrm{P}_{1}, \mathrm{~K}_{1}, \mathrm{~N}_{2}, \mathrm{M}_{2}\right.$, and $\left.\mathrm{S}_{2}\right)$ were then multiplied together, i.e., $\mathrm{RMS}_{\eta} \times \mathrm{RMS}_{\text {speed }} \times \mathrm{RMS}_{\text {direction }}$; the 
$A_{M}$ and $C_{D}$ that corresponded to the minimum value of the multiplication are, thus, the best global parameters for the model in terms of accuracy. Figure 5 shows the $A_{M}$ (horizontal axis) and $C_{D}$ (vertical axis) variations of the multiplication of the normalized RMS difference. The best values for $A_{M}$ and $C_{D}$ are $150 \mathrm{~m}^{2} \mathrm{~s}^{-1}$ and $0.0015 \sim 0.00175$, respectively. Thus, this study adopts $A_{M}=150 \mathrm{~m}^{2} \mathrm{~s}^{-1}$ and $C_{D}=0.0015$ for further runs with the data assimilating technique to increase the overall accuracy of the simulated tides.

\subsection{Model Runs with Tidal Sea Level Nudging}

To improve the accuracy of the model results, the observed tidal sea levels at the ten tide-gauge stations that were not used for the evaluation were assimilated into the model simply through $\eta_{\text {new }}=(1-\varepsilon) \eta^{M}+\varepsilon \eta^{O}$, in which $\eta^{M}$ is the modeled tidal sea level, $\eta^{O}$ is the observed tidal sea level and $\varepsilon(0-1)$ is the nudging factor: the closer the $\varepsilon$ to 1 , the stronger the data assimilation. We used $\varepsilon=0.25$ here to retain the model physics in the lowest order. Sea levels composed from harmonic constants of NAO.99b at depths $>200 \mathrm{~m}$ were also assimilated into the model through the formula described above by replacing $\eta^{O}$ with that composed from NAO.99b.

Figure 6 shows co-tidal charts and barotropic tidal current ellipses derived from the fine-tuned model results for $\mathrm{O}_{1}, \mathrm{P}_{1}, \mathrm{~K}_{1}, \mathrm{~N}_{2}, \mathrm{M}_{2}$, and $\mathrm{S}_{2}$. The corresponding tidal wave characteristics and associated dynamics of the six constituents in this region have been delineated in many papers (e.g., Yanagi and Takao 1998; Fang et al. 1999; Jan et al. 2002). Briefly, tides over the ECS shelf and the Taiwan
Strait are dominated by the semidiurnal $\mathrm{M}_{2}$ constituent, and its maximum amplitude, $\sim 2 \mathrm{~m}$, appears in the middle section of the Taiwan Strait. The abrupt decrease in $\mathrm{M}_{2}$ amplitude in the southern Taiwan Strait has been attributed to the sudden deepening of the topography there (Jan et al. 2004a). The predominance of diurnal tides rather than semidiurnal tides south of Taiwan and in the SCS is clearly seen in Fig. 6.

To quantify the dominant type of tides in the seas around Taiwan, we calculated the form ratio $\left(F_{r}\right)$ which is defined as an amplitude ratio of $\left(\mathrm{O}_{1}+\mathrm{K}_{1}\right) /\left(\mathrm{M}_{2}+\mathrm{S}_{2}\right)$. It is well-known that a tidal type is classified as semidiurnal when $0<F_{r} \leqq 0.25$, as mixed dominantly semidiurnal when $0.25<F_{r} \leqq 1.5$, as mixed predominantly diurnal when $1.5<F_{r} \leqq 3.0$, and as diurnal when $F_{r}>3.0$. Figure 7 shows the spatial variation of the form ratio, which indicates that tides are predominantly semidiurnal in the northern half of the Taiwan Strait, diurnal in the central SCS, and mixed elsewhere.

Harmonic constants of the fifteen constituents derived from carefully tuned model results were summarized into a database (hereafter TWTIDE08) for various applications. Figure 8 illustrates the comparison of the mean RMS difference for the fifteen constituents calculated using tidal sea levels composed by harmonic constants of NAO.99b, CSR4.0 and this study. It is readily seen that the RMS difference of $\mathrm{M}_{2}$ is greatly reduced as compared to that calculated from NAO.99b and CSR4.0 (5.1 cm vs. 13.3 and 18.4 $\mathrm{cm})$. The significant improvement partially results from a better accuracy depth dataset for the ocean bottom topography around Taiwan. The comparisons for the other constituents suggest that the RMS differences are reduced except

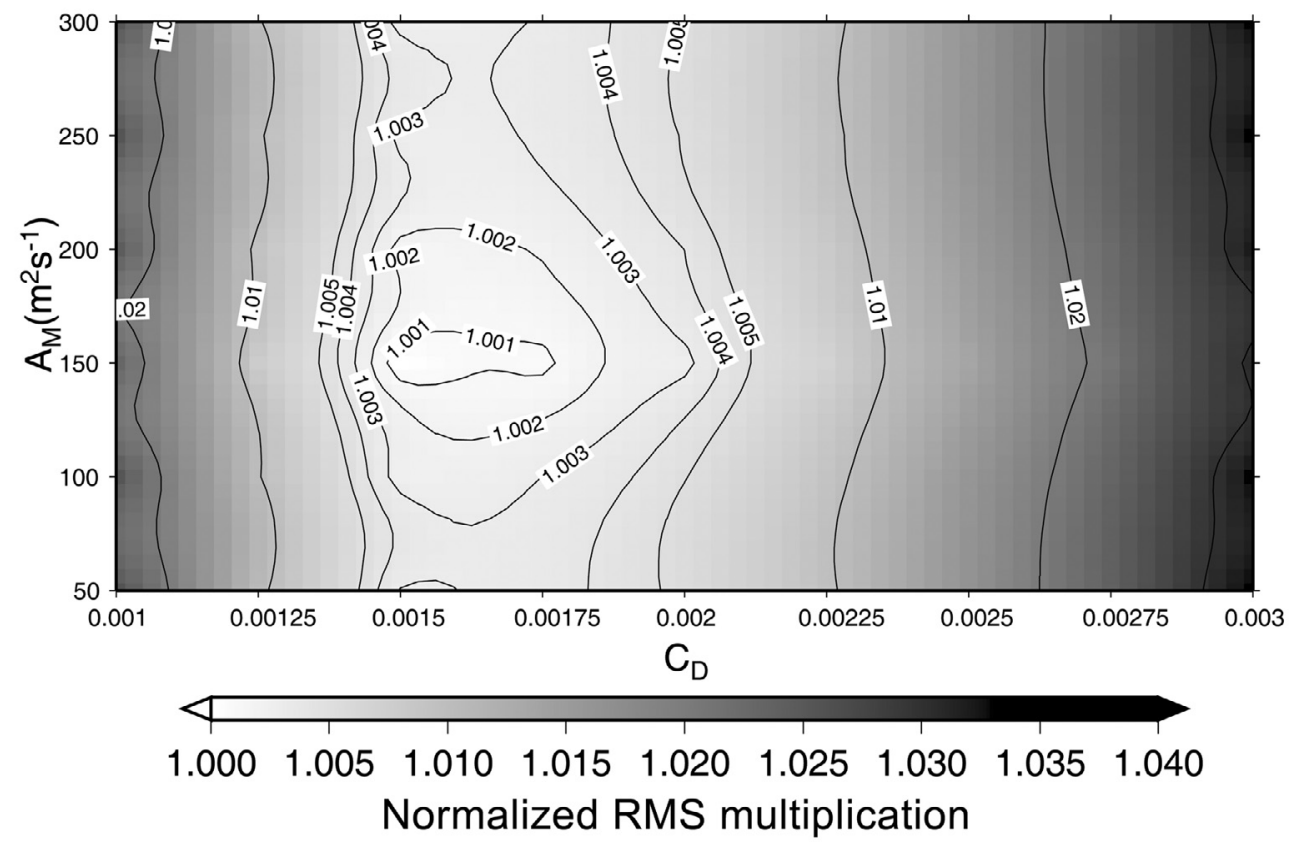

Fig. 5. $A_{M}$ (horizontal axis) and $C_{D}$ (vertical axis) variation for $\mathrm{RMS}_{\eta} \times \mathrm{RMS}_{\text {speed }} \times \mathrm{RMS}_{\text {direction }}$. 

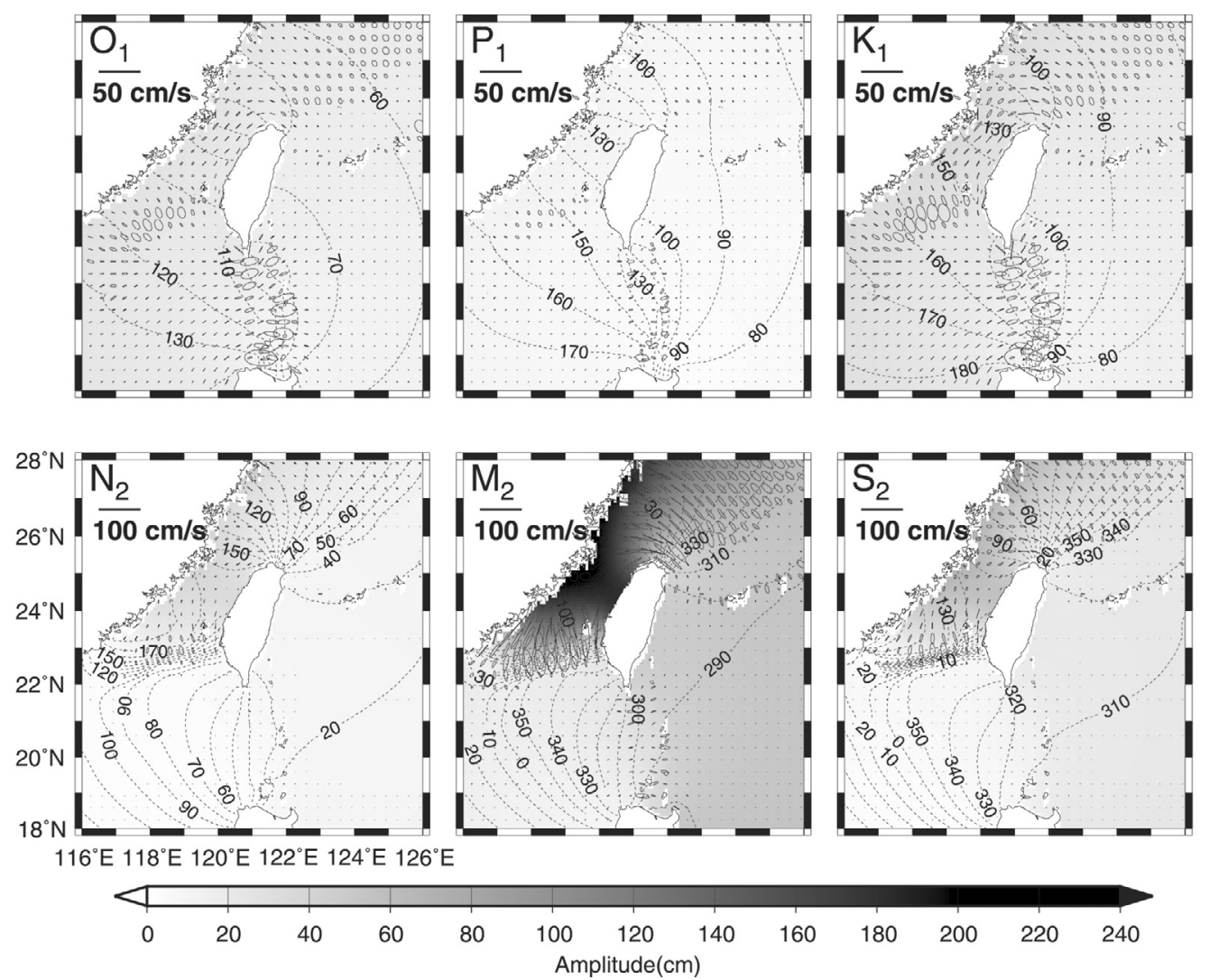

Fig. 6. Co-tidal charts and barotropic tidal current ellipses of the simulated $\mathrm{O}_{1}, \mathrm{P}_{1}, \mathrm{~K}_{1}, \mathrm{~N}_{2}, \mathrm{M}_{2}$, and $\mathrm{S}_{2}$. Amplitudes are indicated by a grey scale. Contours are co-phase lines in degrees.

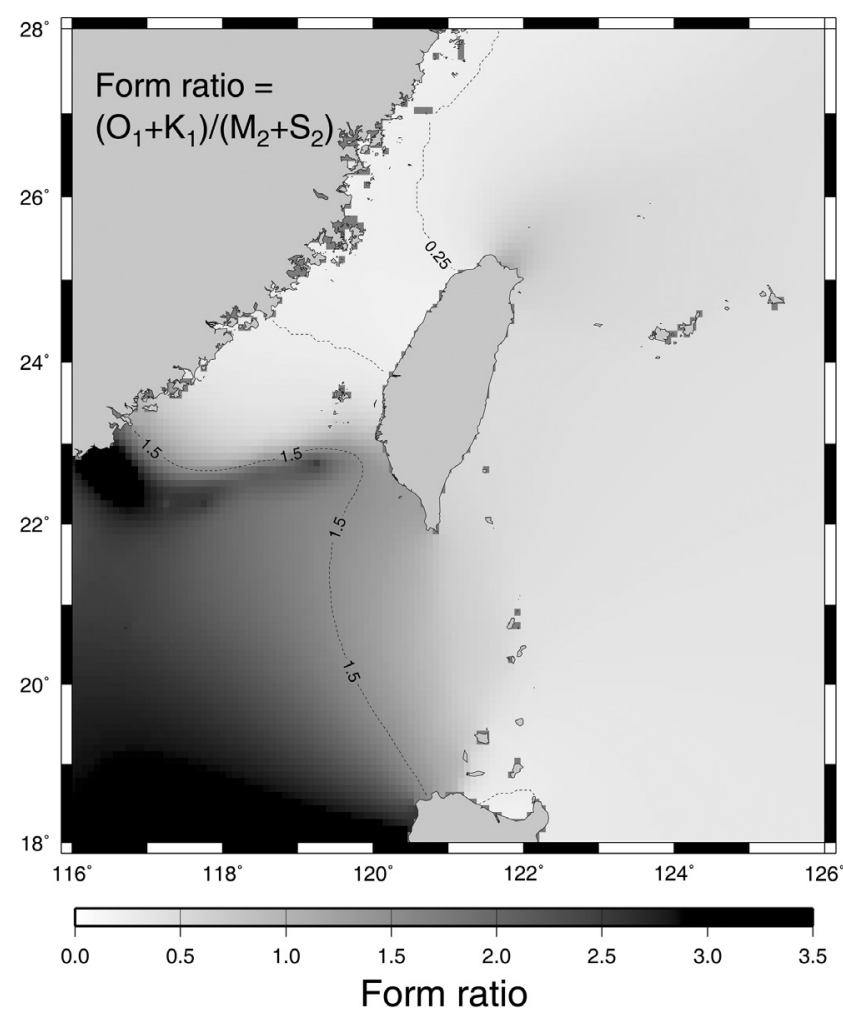

Fig. 7. Spatial variation of the form ratio which is defined as the ratio of amplitude $\left(\mathrm{O}_{1}+\mathrm{K}_{1}\right)$ to $\left(\mathrm{M}_{2}+\mathrm{S}_{2}\right)$. for $\mathrm{O}_{1}$ and $\mathrm{J}_{1}$. The RMS differences of our $\mathrm{O}_{1}$ and $\mathrm{J}_{1}$, which are 0.5 and $0.2 \mathrm{~cm}$, respectively, are slightly larger than that of NAO.99b. However, this does not affect the fact that the accuracy of the tidal sea levels composed by TWTIDE08 is superior to that composed by NAO.99b or CSR 4.0 in the seas around Taiwan.

Since NAO.99b and CSR4.0 do not provide harmonic constants for the barotropic tidal currents, we merely calculated the RMS difference for the $U$ and $V$ components at the six ADCP stations. Table 4 lists the RMS difference of $(U, V)$ for $\mathrm{O}_{1}, \mathrm{~K}_{1}, \mathrm{M}_{2}$, and $\mathrm{S}_{2}$. The model-data differences are larger for $V$ of $\mathrm{O}_{1}\left(6.88 \mathrm{~cm} \mathrm{~s}^{-1}\right)$ at WC3, $U$ of $\mathrm{K}_{1}$ $\left(2.52 \mathrm{~cm} \mathrm{~s}^{-1}\right)$ at PHC and both $U$ of $\mathrm{M}_{2}\left(15.39 \mathrm{~cm} \mathrm{~s}^{-1}\right)$ and $\mathrm{S}_{2}$ $\left(5.86 \mathrm{~cm} \mathrm{~s}^{-1}\right)$ at PHC. The largest RMS difference at station PHC may be caused by the rapid change in bottom depth in the northern reaches of the Penghu Channel. The consequent truncation error in model topography is likely one of the discrepancy sources. The discrepancy may also be caused by the exclusion of the baroclinic tidal currents in the 2-D model, which may affect the depth-averaged tidal current. In reality, baroclinic tides could be generated by the strong tidal current flowing over the steep-rising topography in the vicinity of station PHC (see Fig. 3). Nonetheless, the relative difference at $\mathrm{PHC}$ is acceptable when compared with the harmonic constants of $(U, V)$ in Table 2. The simulated 


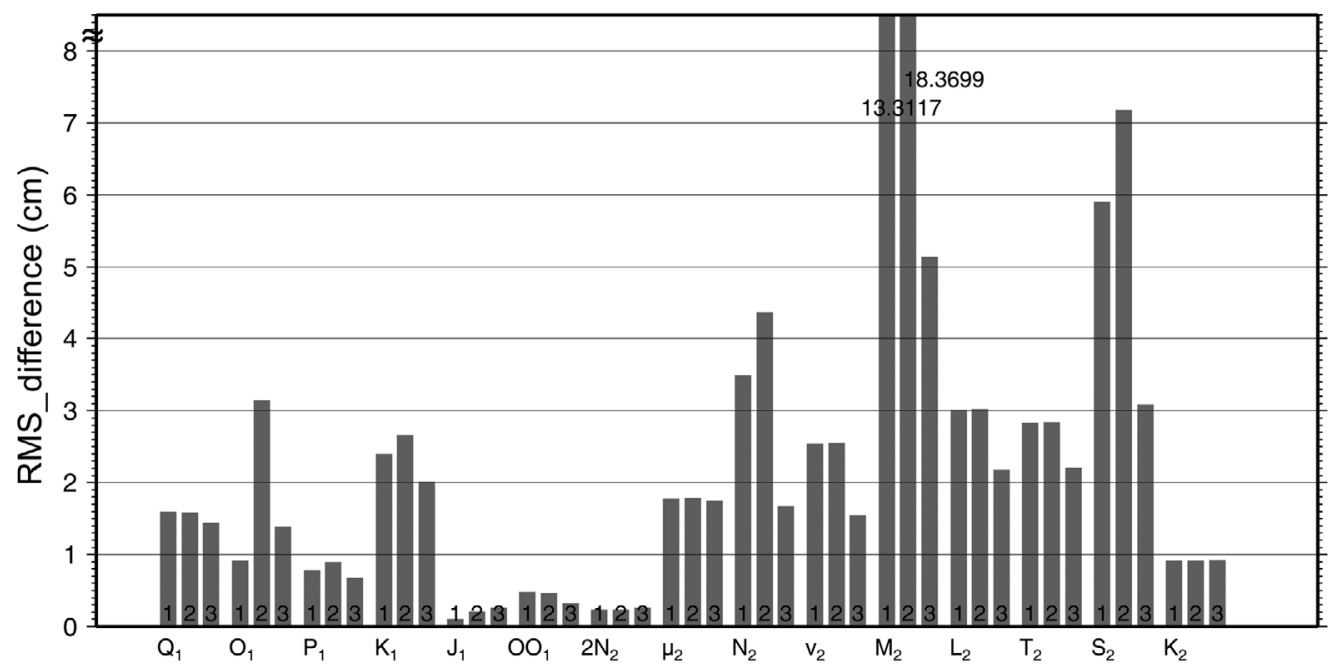

Fig. 8. Comparisons of the mean RMS difference for the fifteen constituents calculated using tidal sea levels composed by harmonic constants of (1) NAO.99b, (2) CSR4.0, and (3) this study.

Table 4. RMS differences $\mathrm{RMS}_{\mathrm{U}}$ and $\mathrm{RMS}_{\mathrm{V}}$ (in $\mathrm{cm} \mathrm{s}^{-1}$ ) respectively for $U$ and $V$ of $\mathrm{O}_{1}, \mathrm{~K}_{1}, \mathrm{M}_{2}$, and $\mathrm{S}_{2}$ at the six bottom-mount ADCP stations.

\begin{tabular}{|c|c|c|c|c|c|c|c|c|}
\hline \multirow[b]{2}{*}{ St. } & \multicolumn{2}{|c|}{$\mathbf{O}_{1}$} & \multicolumn{2}{|c|}{$\mathbf{K}_{1}$} & \multicolumn{2}{|c|}{$\mathbf{M}_{2}$} & \multicolumn{2}{|c|}{$\mathbf{S}_{2}$} \\
\hline & $\mathbf{R M S}_{\mathrm{U}}$ & $\mathbf{R M S}_{\mathrm{V}}$ & $\mathbf{R M S}_{\mathrm{U}}$ & $\mathbf{R M S}_{\mathrm{V}}$ & $\mathbf{R M S}_{\mathrm{U}}$ & $\mathbf{R M S}_{\mathrm{V}}$ & $\mathbf{R M S}_{\mathrm{U}}$ & $\mathbf{R M S}_{\mathrm{V}}$ \\
\hline WC1 & 1.22 & 0.09 & 0.14 & 1.51 & 0.32 & 3.06 & 0.64 & 1.44 \\
\hline WC2 & 1.10 & 0.63 & 0.29 & 0.07 & 2.01 & 4.38 & 0.55 & 0.83 \\
\hline WC3 & 0.34 & 6.88 & 1.02 & 0.53 & 0.68 & 1.21 & 0.75 & 0.07 \\
\hline WC4 & 0.39 & 1.15 & 1.47 & 0.40 & 2.04 & 1.34 & 0.05 & 0.81 \\
\hline EWC & 0.44 & 0.37 & 1.58 & 0.90 & 2.84 & 2.40 & 1.28 & 1.47 \\
\hline PHC & 2.04 & 0.70 & 2.52 & 0.22 & 15.39 & 1.80 & 5.86 & 2.59 \\
\hline
\end{tabular}

tidal currents at $\mathrm{WC} 1$ have the largest relative error, which may be attributed to the poor resolution of the complex local coastal geometry.

\subsection{Energetics of Barotropic Tides}

Tidal energetics (i.e., barotropic tidal energy flux and energy dissipation rate) are useful parameters for discussing the dynamics of tidal waves. The barotropic tidal energy flux along $x$ and $y$ directions was calculated as $\rho_{0} g(\eta U)$ and $\rho_{0} g(\eta V)$, respectively, where $\rho_{0}$ is a reference density of seawater and the angle brackets indicate the time mean of a tidal cycle. The energy dissipation rate per unit area due to bottom friction was calculated by the formula, $\rho_{0}\left[C_{d} \sqrt{U^{2}+V^{2}}\left(U^{2}, V^{2}\right)\right]$. Figure 9 shows the tidal cycle averaged barotropic energy flux and the associated area-inte- grated bottom frictional dissipation rate for $\mathrm{O}_{1}, \mathrm{~K}_{1}, \mathrm{M}_{2}$ (upper panel), $P_{1}, N_{2}$, and $S_{2}$ (lower panel). As shown in Fig. 9, the tidal waves in this region are primarily supported by the $\mathrm{O}_{1}, \mathrm{~K}_{1}$, and $\mathrm{M}_{2}$ constituents. Among the three constituents, $\mathrm{M}_{2}$ possesses the largest energy flux, $\sim 150 \mathrm{~kW} \mathrm{~m}^{-1}$, in the northwest Pacific Ocean, the ECS shelf and the Taiwan Strait. The westward-propagating energy fluxes of $\mathrm{O}_{1}$ and $\mathrm{K}_{1}$ are comparable in the Luzon Strait and the northern SCS, which support barotropic tidal motion in the SCS. The energy flux shown in Fig. 9 indicates that the dominant tide in the Taiwan Strait is a southward-propagating $\mathbf{M}_{2}$. Only a small fraction of northward-propagating $\mathrm{M}_{2}$ energy flux turns anti-cyclonically around the southern tip of Taiwan and then reaches the southwestern Taiwan Strait. This feature indicates that tidal characteristics in the Taiwan Strait are controlled by the interaction between the southward- 

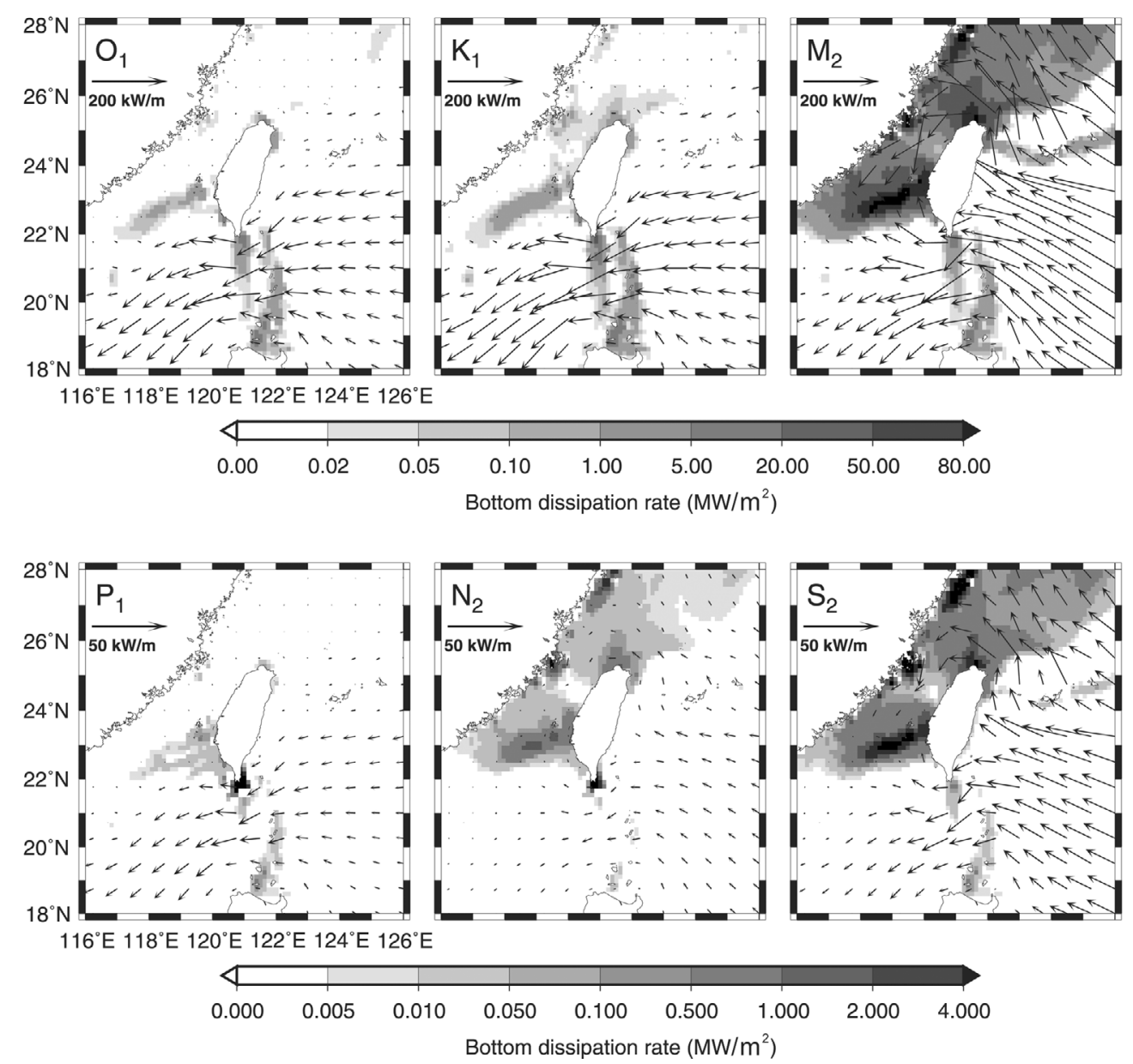

Fig. 9. Barotropic tidal energy flux and dissipation rate due to bottom friction for $\mathrm{O}_{1}, \mathrm{~K}_{1}, \mathrm{M}_{2}$ (upper panel), $\mathrm{P}_{1}, \mathrm{~N}_{2}$, and $\mathrm{S}_{2}$ (lower panel). Note that scales of energy flux and bottom dissipation rate for upper and lower panels are different.

propagating $\mathrm{M}_{2}$ wave and the abruptly deepening topography in the southern Strait (Jan et al. 2004a) rather than by the collision of two opposite waves proposed by Juang et al. (2001) and Lin et al. (2001).

Figure 9 also indicates that a higher $\mathrm{M}_{2}$ barotropic tidal energy dissipation rate due to bottom friction occurs over the shallow shoal in the southwestern Taiwan Strait, at the northern and southern tips of Taiwan, and along the Ryukyu Island Chain and two topographic ridges in the Luzon Strait (Fig. 9). This aspect of the spatial distribution applies not only for $\mathrm{M}_{2}$ but also for $\mathrm{O}_{1}, \mathrm{P}_{1}, \mathrm{~K}_{1}, \mathrm{~N}_{2}$, and $\mathrm{S}_{2}$. Since the bottom stress and associated bottom dissipation rate depends only on $C_{D}$ and velocity [Eq. (4)], the high dissipation rate regions expectedly locate on the shallow shelf and abrupt topographic rise due to the conservation of flow volume transport and around a headland such as that of the southern and northern tips of Taiwan due to a nonlinear effect (Geyer and Signell 1990) (see tidal current ellipses in Fig. 6). The dissipation rate ranges between 50 to $80 \mathrm{MW} \mathrm{m}{ }^{-2}$ (1 MW $=10^{6} \mathrm{~W}$ ) in those regions for $\mathrm{M}_{2}$. In comparison with $\mathrm{M}_{2}$, the energy dissipation due to bottom friction is quite small $\left(<4 \mathrm{MW} \mathrm{m}^{-2}\right)$ for the other five constituents. The area-integrated mean rates of bottom dissipation in the area from 116 to $126^{\circ} \mathrm{E}$ and from 18 to $28^{\circ} \mathrm{N}$ are $0.120,0.450,0.399$, $0.263,22.390$, and $1.103 \mathrm{GW}\left(1 \mathrm{GW}=10^{9} \mathrm{~W}\right)$ for $\mathrm{O}_{1}, \mathrm{P}_{1}$, $\mathrm{K}_{1}, \mathrm{~N}_{2}, \mathrm{M}_{2}$, and $\mathrm{S}_{2}$, respectively. It should be noted that, due to the lack of barotropic to baroclinic tidal energy conversion in a 2-D tide model, the above-mentioned dissipation mechanism in the shallow water region cannot be regarded as the real situation. In 3-D baroclinic tide simulations, the barotropic to baroclinic tidal energy conversion rate can be as high as $25 \%$ of the incident barotropic tidal energy, e.g., in the Luzon Strait (Niwa and Hibiya 2004; Jan et al. 2008).

\section{CONCLUSIONS}

A $1 / 12^{\circ}, 2-\mathrm{D}$ regional barotropic tide model with an accurate bottom topography was carefully tuned to simulate tides of fifteen constituents $\left(\mathrm{Q}_{1}, \mathrm{O}_{1}, \mathrm{P}_{1}, \mathrm{~K}_{1}, \mathrm{~J}_{1}, \mathrm{OO}_{1}, 2 \mathrm{~N}_{2}\right.$, $\mu_{2}, N_{2}, v_{2}, M_{2}, L_{2}, T_{2}, S_{2}$, and $K_{2}$ ) individually in the East Asian seas. The tidal sea levels composed by observed har- 
monic constants at ten coastal tide-gauge stations around Taiwan were also assimilated into the model to increase the accuracy of the simulated tidal sea levels and currents. The RMS differences of the tidal sea levels averaged over the other ten reference tide-gauge stations around Taiwan are $1.3,0.7,2.0,1.6,5.1$, and $3.1 \mathrm{~cm}$ for the six major constituents $\mathrm{O}_{1}, \mathrm{P}_{1}, \mathrm{~K}_{1}, \mathrm{~N}_{2}, \mathrm{M}_{2}$, and $\mathrm{S}_{2}$, respectively. The most significant improvement of the simulated tidal sea level is on $\mathbf{M}_{2}$. For comparison, similar mean RMS differences to that of $\mathrm{M}_{2}$ at the ten reference tide-gauge stations are $13.3 \mathrm{~cm}$ from NAO.99b and $18.4 \mathrm{~cm}$ from CSR4.0. The mean RMS difference for each of the fifteen constituents is generally smaller than that calculated using harmonic constants of NAO.99b and CSR4.0. The RMS difference of barotropic $(U, V)$ averaged over the six bottom-mount ADCP stations is $(0.92,1.64),(1.17,0.61),(3.88,2.37)$, and $(1.52,1.20)$ $\mathrm{cm} \mathrm{s}^{-1}$ for $\mathrm{O}_{1}, \mathrm{~K}_{1}, \mathrm{M}_{2}$, and $\mathrm{S}_{2}$, respectively. These values and associated uncertainty are reasonable for tidal current simulation. Accordingly, a database (TWTIDE08) for tidal sea level and current harmonic constants of the fifteen constituents is established for further applications.

The tidal energetics derived from the model results indicate that the barotropic tidal energy in the seas around Taiwan is primarily supported by $\mathrm{O}_{1}, \mathrm{~K}_{1}$, and $\mathrm{M}_{2}$. In comparison, $\mathrm{M}_{2}$ possesses the largest energy flux in the northwest Pacific Ocean, the ECS shelf and the Taiwan Strait; while the energy fluxes of $\mathrm{O}_{1}$ and $\mathrm{K}_{1}$ are comparable to $\mathrm{M}_{2}$ only in the Luzon Strait and the SCS, which are the major sources of energy supporting barotropic tides in the SCS. The energy flux also indicates that barotropic tidal characteristics in the Taiwan Strait are primarily controlled by the southward-propagating $\mathrm{M}_{2}$ wave rather than the collision of two opposite waves in the middle reaches. The barotropic tidal energy of all the six constituents is mostly dissipated by bottom friction over the shallow shoal in the southern Taiwan Strait.

Acknowledgements This study was granted by the National Science Council and National Applied Research Laboratories in Taiwan under grant numbers SC95-2611-M-008-004MY3 and 97-TORI-007. The tidal sea level data collected at coastal tide-gauge stations were mostly purchased from the Central Weather Bureau of Taiwan. The ADCP measurements were performed during the project "TSNOW".

\section{REFERENCES}

Blumberg, A. F. and L. H. Kantha, 1985: Open boundary condition for circulation models. J. Hydraul. Eng., 111, 237-255, doi: 10.1061/(ASCE)0733-9429(1985) 111:2(237). [Link]

Blumberg, A. F. and G. F. Mellor, 1987: A description of a three dimensional coastal ocean circulation model. In: Heaps, N. (Ed.), Three-Dimensional Coastal Ocean
Models, Vol. 4, 1-16, AGU, Washington DC.

Eanes, R. J. and S. V. Bettadpur, 1996: Ocean tides from two years of TOPEX/POSEIDON altimetry (abstract). Eos, Trans., AGU, 75, Fall Meet. Suppl., 61 pp.

Fang, G., Y. K. Kwok, K. Yu, and Y. Zhu, 1999: Numerical simulation of principal tidal constituents in the South China Sea, Gulf of Tonkin and Gulf of Thailand. Cont. Shelf Res., 19, 845-869, doi: 10.1016/S0278-4343 (99)00002-3. [Link]

Foreman, M. G. G. and R. F. Henry, 1977: Tidal analysis based on high and low water observations. Pacific Marine Science Report 79-15, Institute of Ocean Sciences, Patricia Bay, 36 pp.

Foreman, M. G. G., R. F. Henry, R. A. Walters, and V. A. Ballantyne, 1993: A finite element model for tides and resonance along the north coast of British Columbia. J. Geophys. Res., 98, 2509-2531, doi: 10.1029/92JC02470. [Link]

Geyer, W. R. and R. P. Signell, 1990: Measurements of tidal flow around a headland with a shipboard acoustic Doppler profiler. J. Geophys. Res., 95, 3189-3197, doi: 10.1029/JC095iC03p03189. [Link]

Jan, S., C. S. Chern, and J. Wang, 2002: Transition of tidal waves from the East to South China Seas over the Taiwan Strait: Influence of the abrupt step in the topography. J. Oceanogr., 58, 837-850, doi: 10.1023/A:1022827330693. [Link]

Jan, S. C. S. Chern, J. Wang, and S. Y. Chao, 2004a: The anomalous amplification of M2 tide in the Taiwan Strait. Geophys. Res. Lett., 31, L07308, doi: 10.1029/ 2003GL019373. [Link]

Jan, S., Y. H. Wang, D. P. Wang, and S. Y. Chao, 2004b: Incremental inference of boundary forcing for a three-dimensional tidal model: Tides in the Taiwan Strait. Cont. Shelf Res., 24, 337-351, doi: 10.1016/j. csr.2003.11.005. [Link]

Jan, S., C. S. Chern, J. Wang, and S. Y. Chao, 2007: Generation of diurnal $\mathrm{K}_{1}$ internal tide in the Luzon Strait and its influence on surface tide in the South China Sea. J. Geophys. Res., 112, C06019, doi: 10.1029/2006J C004003. [Link]

Jan, S., R. C. Lien, and C. H. Ting, 2008: Numerical study of baroclinic tides in Luzon Strait. J. Oceanogr., 64, 789-802, doi: 10.1007/s10872-008-0066-5. [Link]

Juang, W. J., M. C. Lin, and W. J. Liou, 2001: Peculiar appearance of nearly symmetrical flooding time along the western coast of Taiwan. Chin. J. Mech., 17, 211-220.

Kang, S. K., S. R. Lee, and H. J. Lie, 1998: Fine grid tidal modeling of the Yellow and East China Seas. Cont. Shelf Res., 18, 739-772, doi: 10.1016/S0278-4343(98) 00014-4. [Link]

Kantha, L. H. and C. A. Clayson, 2000: Numerical models of oceans and oceanic processes - Ch. 6 Tides and tidal modeling. International Geophysics Series, V. 66, 
Academic Press, California, 940 pp.

Lefevre, F., C. Le Provost, and F. H. Lyard, 2000: How can we improve a global ocean tide model at a regional scale? A test on the Yellow Sea and the East China Sea. J. Geophys. Res., 105, 8707-8725, doi: 10.1029/ 1999JC900281. [Link]

Lin, M. C., W. J. Juang, and T. K. Tsay, 2001: Anomalous amplification of semidiurnal tides along the western coast of Taiwan. Ocean Eng., 28, 1171-1198, doi: 10.1016/ S0029-8018(00)00049-4. [Link]

Matsumoto,K., T. Takanezawa, and M.Ooe, 2000: Ocean tide models developed by assimilating TOPEX/POSEIDON altimeter data into hydrodynamical model: A global model and a regional model around Japan. J. Oceanogr., 56, 567-581, doi: 10.1023/A:1011157212596. [Link]

Niwa, Y. and T. Hibiya, 2004: Three-dimensional numerical simulation of M2 internal tides in the East
China Sea, J. Geophys. Res., 109, C04027, doi: 10.1029/2003JC001923. [Link]

Pugh, D. T., 1987: Tides, surges and mean sea-level. Wiley, Chichester, $471 \mathrm{pp}$.

Ray, R. D., 2001: Estimates of internal tide energy fluxes from TOPEX/POSEIDON altimetry: Central North Pacific. Geophys. Res. Lett., 28, 1259-1262, doi: 10.1029/ 2000GL012447. [Link]

Ray, R. D. and D. E. Cartwright, 1998: Ocean self-attraction and loading in numerical tidal models. Mar. Geodesy, 21, 181-192, doi: 10.1080/01490419809388134. [Link]

Yanagi, T. and T. Takao, 1998: A numerical simulation of tides and tidal currents in the South China Sea. Acta Oceanogr. Taiwan., 37, 1, 17-29.

Ye, A. L. and I. S. Robinson, 1983: Tidal dynamics in the South China Sea. Geophys. J. R. Astr. Soc., 72, 691-707. 